\title{
Determination of ochratoxin A in wine grapes: comparison of extraction procedures and method validation
}

\author{
Rita Serra $^{\mathrm{a}}$, Carla Mendonça ${ }^{\mathrm{a}}$, Luís Abrunhosa ${ }^{\mathrm{a}}$, Amedeo Pietri ${ }^{\mathrm{b}}$, Armando Venâncio ${ }^{\mathrm{a}, *}$ \\ ${ }^{a}$ Centro de Engenharia Biológica, Universidade do Minho, Campus de Gualtar, 4710-057 Braga, Portugal \\ ${ }^{\mathrm{b}}$ Instituto di Scienze degli Alimenti e della Nutrizione, Facoltà di Agraria UCSC, Via Emilia Parmense 84, 29100 Piacenza, Italy
}

Received 10 July 2003; received in revised form 15 September 2003; accepted 26 September 2003

Available online 7 November 2004

\begin{abstract}
A method for determination of ochratoxin A (OTA) in wine grapes is described, using extraction with a hydrogen carbonate and polyethylene glycol (PEG) solution (5\% $\mathrm{NaHCO}_{3}$ and $1 \%$ PEG 8000 ), followed by immunoaffinity clean-up and liquid chromatography with fluorescence detection. Validation was made with spiked samples, in levels of 0.05 and $1 \mu \mathrm{g} \mathrm{kg}^{-1}$, with average recovery rates of $76 \%$ and relative standard deviations in repeatability and intermediate precision conditions of 8 and 12\%, respectively. The limit of detection and limit of quantification in grapes were established at 0.004 and $0.007 \mu \mathrm{g} \mathrm{kg}^{-1}$, respectively. To evaluate further the accuracy and efficiency of this method, naturally contaminated grapes were also analysed by another method that involves extraction with acidified methanol, at levels ranging from 0.05 to $37 \mu \mathrm{g} \mathrm{kg}^{-1}$, and the results compared. A good correlation $(r=0.9996)$ was found, with better performances in terms of precision for the new method. A survey was conducted on wine grapes from 11 Portuguese vineyards, during the harvest of 2002, using the proposed method. OTA was detected in three out of the 11 samples, at levels ranging from 0.035 to $0.061 \mu \mathrm{g} \mathrm{kg}^{-1}$.

The new method meets all the criteria of the European Commission directive 2002/26/CE, that lays down the sampling and the analysis methods for the official control of OTA levels in foodstuffs. It is reliable for low levels of contamination ( $\left.\mathrm{ng} \mathrm{kg}^{-1}\right)$, and avoids the use of organic solvents in the extraction step.
\end{abstract}

(c) 2003 Elsevier B.V. All rights reserved.

Keywords: Ochratoxin A; Wine; Grapes; Method validation; Mycotoxin

\section{Introduction}

Ochratoxin A (OTA) (Fig. 1) is a mycotoxin with nephrotoxic and immunosuppressive properties that has been found out in several food commodities. In studies concerning the intake of the mycotoxin by populations in the European Union (EU), wine is considered the second major source of intake, corresponding to $10 \%$ [1]. The food organisations recommend lowering the levels of OTA present in food commodities to the lowest value technologically feasible. Wine is a natural product, important to the European economy and populations, with proven health benefits, and therefore is important to assure that it is free of harmful contaminants. The mycotoxin has been detected in wines at levels ranging from below the limit of detection to $15.6 \mu \mathrm{g} \mathrm{kg}^{-1}$. The OIV has proposed a limit for OTA in wine of $2 \mu \mathrm{g} \mathrm{l}^{-1}$. In a recent survey of 340 Portuguese wines, the mycotoxin was always

\footnotetext{
* Corresponding author. Fax: +351-253678986.

E-mail address: avenan@deb.uminho.pt (A. Venâncio).
}

detected at levels below the limit of $2 \mu \mathrm{g} \mathrm{kg}^{-1}$ [2], with most of the wines analysed (338) not exceeding $0.5 \mu \mathrm{g} 1^{-1}$.

There are ongoing projects to evaluate the risk of wine contamination with OTA in different European countries, including Portugal. Work has been done in order to establish the causes of OTA presence in wine. Studies indicated that filamentous fungi belonging to black aspergilli, namely A. carbonarius and some strains of A. niger, are responsible for OTA production in grapes [3], leading to the presence of the mycotoxin in wine. However, as far as we are aware, no method has yet been validated for determination of OTA in grapes. In order to study the conditions that favour OTA presence in wine, the determination of the mycotoxin in grapes is necessary.

In wine, methods of analysis for OTA were described with extraction procedures using toluene [4], chloroform [5], or a hydrogen carbonate and PEG solution [6]. Immunoaffinity columns (IACs) have been widely used as a clean-up tool and their use is highly recommended, allowing the isolation of the analyte from most matrix interferences, due to its 


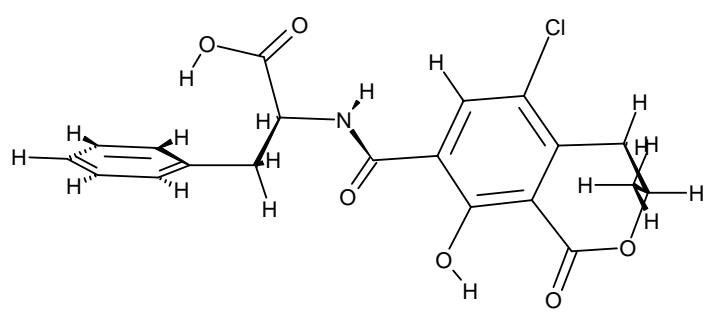

Fig. 1. Chemical formula of OTA.

specificity, and analyte preconcentration, necessary when low limits of detection are required. When immunoaffinity clean-up is coupled with liquid chromatography combined with fluorescence detection (LC-FL), levels of detection as low as $0.01 \mu \mathrm{g} \mathrm{kg}^{-1}$ are achieved [7]. The method described by Visconti et al. [6] was proposed as the official method for determination of OTA in wines, involving dilution with hydrogen carbonate and PEG solution followed by IAC clean-up and LC-FL detection. This method was used as a starting point to develop a method for analysis of grapes. However, grapes are a solid product, even if with a high level of water. In order to evaluate if the extraction of OTA from grapes with hydrogen carbonate solution is efficient, validation was done using spiked and naturally contaminated samples, as recommended by Anklam et al. [8]. Furthermore, to evaluate the accuracy of the method, naturally contaminated grapes were also analysed by another method validated for a similar matrix (dried vine fruits [9]) that involves an extraction with acidified methanol and the results were compared.

The method described here was used in a survey of Portuguese grapes destined for wine production, collected in the harvest of 2002.

\section{Experimental}

\subsection{Chemicals and materials}

HPLC grade solvents and pro-analysis grade chemicals were delivered from Merck (Lisbon). The Ochra Test IACs were obtained from Vicam (Boston, MA).

\subsection{Instrumentation}

\subsubsection{LC with $F L$}

The samples were analysed using reverse phase LC equipped with a Jasco FP-920 fluorescence detector (330 nm excitation wavelength; $460 \mathrm{~nm}$ emission wavelength). Chromatographic separations were performed on a Waters Spherisorb ODS2 $(4.6 \mathrm{~mm} \times 250 \mathrm{~mm} ; 5 \mu \mathrm{m})$ column, fitted with a pre-column with the same stationary phase and thermostatted at $30^{\circ} \mathrm{C}$. The mobile phase was acetonitrile:water:acetic acid (99:99:2 by volume) at $1.0 \mathrm{ml} \mathrm{min}^{-1}$. The injection volume was $100 \mu l$.

\subsubsection{Standard preparation}

OTA was purchased from Sigma, in crystallised form. A stock solution of $20 \mu \mathrm{g} \mathrm{I}^{-1}$ was prepared in toluene-acetic acid (99:1) and kept at $-20^{\circ} \mathrm{C}$. The OTA concentration of this solution was determined accurately by UV spectrophotometry at $331 \mathrm{~nm}$ and checked regularly each time a new working solution was needed. A working solution $\left(2 \mu \mathrm{gl}^{-1}\right)$ was prepared, and the OTA concentration of this solution was also checked by UV spectrophotometry. From the working solution, the standards for LC calibration and addition experiments were prepared. For standard addition experiments, OTA was added in $1 \mathrm{ml}$ of methanol.

\subsection{Samples}

Grapes were collected in 11 Portuguese vineyards located in four winemaking regions (Vinhos Verdes, Douro, Ribatejo and Alentejo), during the harvest of 2002, according to the sampling plan described in [3]: in each vineyard, 10 bunches were harvested along two crossing diagonal transects. The samples were taken to the laboratory in closed paper bags, transported in cooled boxes, and analysed in the shortest time possible, always before $24 \mathrm{~h}$ after collection. The berries were separated from the rachis, and stored frozen at $-20^{\circ} \mathrm{C}$. For each vineyard, samples from 1 to $3 \mathrm{~kg}$ were collected.

To obtain naturally contaminated samples, table grapes (variety Dominga) were sprayed with a spore suspension $\left(10^{3}\right.$ spores $\left.\mathrm{ml}^{-1}\right)$ of an OTA producing strain of $A$. carbonarius isolated from grape must and preserved in the MUM culture collection [10]; the berries were incubated for 3 and 6 days in a plastic box at $25^{\circ} \mathrm{C}$, to achieve different levels of contamination.

\subsection{Sample preparation}

The entire sample was slightly unfrozen and homogenised in a blender (Moulinex) for ca. $10 \mathrm{~min}$, with $1 \mathrm{~min}$ rest each $3 \mathrm{~min}$, to prevent sample heating. From this homogenate, three aliquots of $50 \mathrm{~g}$ were taken. One was immediately analysed, the other two were frozen, for eventual confirmatory studies and replicate analysis.

\subsubsection{Sample extraction with hydrogen carbonate and PEG solution}

The sample $(50 \mathrm{~g})$ was weighed in a $250 \mathrm{ml}$ graduated glass beaker, and was made to $150 \mathrm{ml}$ with solution A (5\% $\mathrm{NaHCO}_{3}, 1 \%$ PEG 8000). The mixture was poured into a $250 \mathrm{ml}$ centrifuge bottle and put under magnetic mixing for ca. $30 \mathrm{~min}$, then centrifuged at $8500 \mathrm{rpm}$ for $20 \mathrm{~min}$, at $4{ }^{\circ} \mathrm{C}$. The supernatant was filtered through a glass microfibre filter $(1.5 \mu \mathrm{m}$ pore size) and the filtrate collected in a graduated cylinder; $20 \mathrm{ml}$ of this filtrate was passed through the IAC.

\subsubsection{Sample extraction with acidified methanol [9]}

This procedure was described for dried vine fruit and was adapted to grapes. The sample $(50 \mathrm{~g})$ was mixed with $50 \mathrm{ml}$ 
of methanol and $5 \mathrm{ml}$ of $0.1 \mathrm{M}$ orthophosphoric acid in a blender for $2 \mathrm{~min}$. The mixture was filtered through a glass microfibre filter $(1.5 \mu \mathrm{m}$ pore size $)$ and the filtrate collected in a graduated cylinder. An aliquot $(12.5 \mathrm{ml})$ of the filtrate was diluted to $100 \mathrm{ml}$ with solution $\mathrm{A}$, and the diluted extract was passed through the IAC.

\subsubsection{Immunoaffinity clean-up}

The procedure followed was the one indicated by Visconti et al. [6], that consists of passing the sample extract diluted with solution $\mathrm{A}$ through the IAC, and washing the IAC with $5 \mathrm{ml}$ of solution $\mathrm{B}\left(2.5 \% \mathrm{NaCl}, 0.5 \% \mathrm{NaHCO}_{3}\right)$, followed by $5 \mathrm{ml}$ of deionised water. OTA was eluted with $2 \mathrm{ml}$ of methanol, completely evaporated with a gentle stream of nitrogen and redissolved in $1 \mathrm{ml}$ of mobile phase.

\subsection{Quantification, replicate analysis and confirmatory studies}

Samples yielding a peak at a retention time similar to the OTA standard peak (ca. $11 \mathrm{~min}$ ) were considered presumptive positives, and the presence of OTA was confirmed by other means. When OTA levels were below $0.02 \mu \mathrm{g} \mathrm{kg}^{-1}$, the identity of OTA was confirmed by standard addition. Otherwise, confirmation was made by methyl ester formation after derivatization of the extracts with $\mathrm{BF}_{3}$ as described by Hunt et al. [11]. All the results presented are uncorrected for recovery. All positive samples were analysed in duplicate.

\subsection{Method performance}

\subsubsection{Standard addition experiments}

In standard addition experiments, six replicates were made on different days in order to estimate the recovery rate, relative standard deviation $(R S D)_{r}$ and $R_{R}$ (intermediate precision), at two concentrations ( 0.05 and $1 \mu \mathrm{g} \mathrm{kg}^{-1}$ ). OTA was added to $500 \mathrm{~g}$ of homogenised grapes previously analysed with negative results for OTA presence. The sample was allowed to equilibrate for $1 \mathrm{~h}$ and after that, it was blended for ca. $1 \mathrm{~min}$. Six aliquots of $50 \mathrm{~g}$ each were taken, three were immediately analysed and the other three were frozen at $-20{ }^{\circ} \mathrm{C}$ for analysis on another day.

The recovery rates varied according to the solvent used in spiking. When assessing the solvent to be used for spiking, acetonitrile, methanol and toluene-acetic acid (99:1) were used. Homogenised grapes were spiked with OTA to obtain a final concentration of $1 \mu \mathrm{g} \mathrm{kg}^{-1}$, and were diluted with solution A, as described above. An aliquot of $4 \mathrm{ml}$ of solution $\mathrm{A}$ was acidified with $2 \mathrm{ml}$ of $1 \mathrm{M} \mathrm{HCl}$ and extracted twice with chloroform. The emulsion was broken with gentle magnetic agitation. This study was performed in duplicate. Higher recoveries were obtained for methanol $(68.4 \%)$ and toluene-acetic acid (86.3\%). For this study, methanol was used because of its miscibility with the matrix, allowing better homogenisation. These results support the recommendations made for the use of certified reference materials (CRMs) and naturally contaminated products in method validation for mycotoxin analysis in foods. As far as we know, no CRMs exist for grapes. Therefore, validation was carried out with naturally contaminated grapes.

\subsection{Comparison of methods with naturally contaminated grapes}

Naturally contaminated grapes were analysed by both methods. To obtain different concentrations, dilutions of contaminated material with blank material were made in the appropriated mass ratios, to achieve $500 \mathrm{~g}$ of sample, and then the mixtures were blended for ca. $1 \mathrm{~min}$.

\subsubsection{Calibration}

Fresh standard solutions were prepared daily. The aliquots of working solution were evaporated to dryness with a nitrogen stream and redissolved in the mobile phase. Four-point graphs were obtained with concentrations of $0.05,0.1,1$ and $10 \mu \mathrm{gl}^{-1}$. Calibration graphs were drawn by linear regression of the least-squares method using peak height of the standard as response vs. concentration. The correlation coefficient was $\geq 0.9999$. The limit of detection was $0.03 \mu \mathrm{gl}^{-1}$, calculated as three times the standard deviation of the $y$-residuals of the calibration graph. The limit of quantification given is the lowest concentration of the OTA standard used in the calibration.

\section{Results and discussion}

\subsection{Validation with spiked samples}

The mean recovery for spiked samples ranged from 72.5 to $80.5 \%$ (Table 1 ). The recovery rates and precision values obtained are acceptable, according to the European guidelines for method validation in the European Commission directive 2002/26/CE [12] and according to the proposal of Gilbert and Anklam [13], for the validation of analytical methods for determining mycotoxins in foodstuffs.

Table 1

Method validation parameters for determination of OTA in wine grapes using extraction with the proposed method at two OTA concentrations

\begin{tabular}{lcc}
\hline Parameter & \multicolumn{2}{c}{ OTA concentration $\left(\mu \mathrm{g} \mathrm{kg}^{-1}\right)$} \\
\cline { 2 - 3 } & 0.05 & 1 \\
\hline Mean recovery \pm S.D. $^{\mathrm{a}}(\%)$ & $80.0 \pm 13.4$ & $71.4 \pm 5.0$ \\
$\mathrm{RSD}_{\mathrm{r}}^{\mathrm{b}}(\%)$ & 9.1 & 7.4 \\
$\mathrm{RSD}_{\mathrm{R}}{ }^{\mathrm{b}}(\%)$ & 16.8 & 7.0 \\
Limit of detection in grapes $_{\text {Limit of quantification in grapes }}$ & 0.004 \\
\hline
\end{tabular}

\footnotetext{
${ }^{\text {a }}$ Standard deviation ( $n=6$ replicates).

${ }^{\mathrm{b}}$ Relative standard deviation.
} 
Table 2

Analysis of OTA content of naturally contaminated grapes diluted with blank samples in different mass ratios by the two extraction procedures tested here, the proposed method and that of MacDonald et al. method [9]

\begin{tabular}{lcc}
\hline $\begin{array}{l}\text { Mass ratio of contaminated } \\
\text { sample:blank sample }\end{array}$ & $\begin{array}{l}\text { Present method } \\
\left(\mu \mathrm{gg}^{-1}\right)\end{array}$ & $\begin{array}{l}\text { MacDonald et al. } \\
\text { method }\left(\mu \mathrm{gg}^{-1}\right)\end{array}$ \\
\hline $1: 500$ & 0.07 & 0.13 \\
$1: 400$ & 0.07 & 0.10 \\
$1: 300$ & 0.09 & 0.09 \\
$1: 200$ & 0.14 & 0.14 \\
$1: 100$ & 0.25 & 0.24 \\
$1: 50$ & 0.53 & 0.62 \\
$1: 10$ & 2.86 & 2.63 \\
$1: 5$ & 5.53 & 4.06 \\
1 & 37.64 & 32.76 \\
$r^{\mathrm{a}}$ (between dilution ratios & 0.998 & 0.997 \\
$\quad$ and OTA result (1:500-1) & & \\
$r^{\mathrm{a}}$ (between dilution ratios & 0.999 & \\
$\quad$ and OTA result in ng kg & & \\
$\quad$ (1:500-1:50)) & & \\
\hline
\end{tabular}

${ }^{a}$ Correlation coefficient.

\subsection{Comparison of extraction procedures using naturally contaminated samples}

Table grapes incubated with an A. carbonarius OTA producing strain for 3 and 6 days were analysed for their OTA content by our method and the method of MacDonald et al. [9]. After 3 days incubation, the OTA content detected in the sample by both methods was $0.06 \mathrm{~g} \mathrm{~kg}^{-1}$. After 6 days incu- bation, two samples were obtained, with an OTA content of 15.50 and $37.64 \mu \mathrm{g} \mathrm{kg}^{-1}$ using the presented method, and 14.00 and $32.76 \mu \mathrm{g} \mathrm{kg}^{-1}$ by the method of MacDonald et al. [9], respectively. From the sample with higher OTA levels, dilutions were made with non-contaminated wine grapes to obtain different concentrations, and the results are shown in Table 2. In Table 3, the correlation coefficients $(r)$ between both methods are given, for different sets of values. The $r$-value obtained between the OTA content of the diluted grapes and the dilution rate (1:500-1) for extraction with solution A was 0.998 and for extraction following MacDonald et al. [9] was 0.997, indicating that both methods show linearity over the concentration range tested. The two methods were compared by linear regression for the whole set of values $(n=11)$, and the results are presented in Fig. 2 on a double logarithmic scale. The $r$-value obtained is 0.9997 , and the slope and intercept values are 0.87 and 0.01 , respectively (Table 3 ). The value for the slope differs from the theoretical value of unity by $13 \%$, favouring the method here proposed, and the value for the intercept does not differ significantly from zero.

In the $\mathrm{ng} \mathrm{kg}^{-1}$ concentration range tested (from 0.06 to $\left.0.53 \mu \mathrm{g} \mathrm{kg}^{-1}, n=7\right)$, there is a reasonable correlation coefficient between the results of the methods compared $(r=$ 0.987 ). The slope differs significantly from unity by $12 \%$, favouring the method that involves extraction with acidified methanol, and the intercept does not differ significantly from zero. However, the correlation coefficients between each

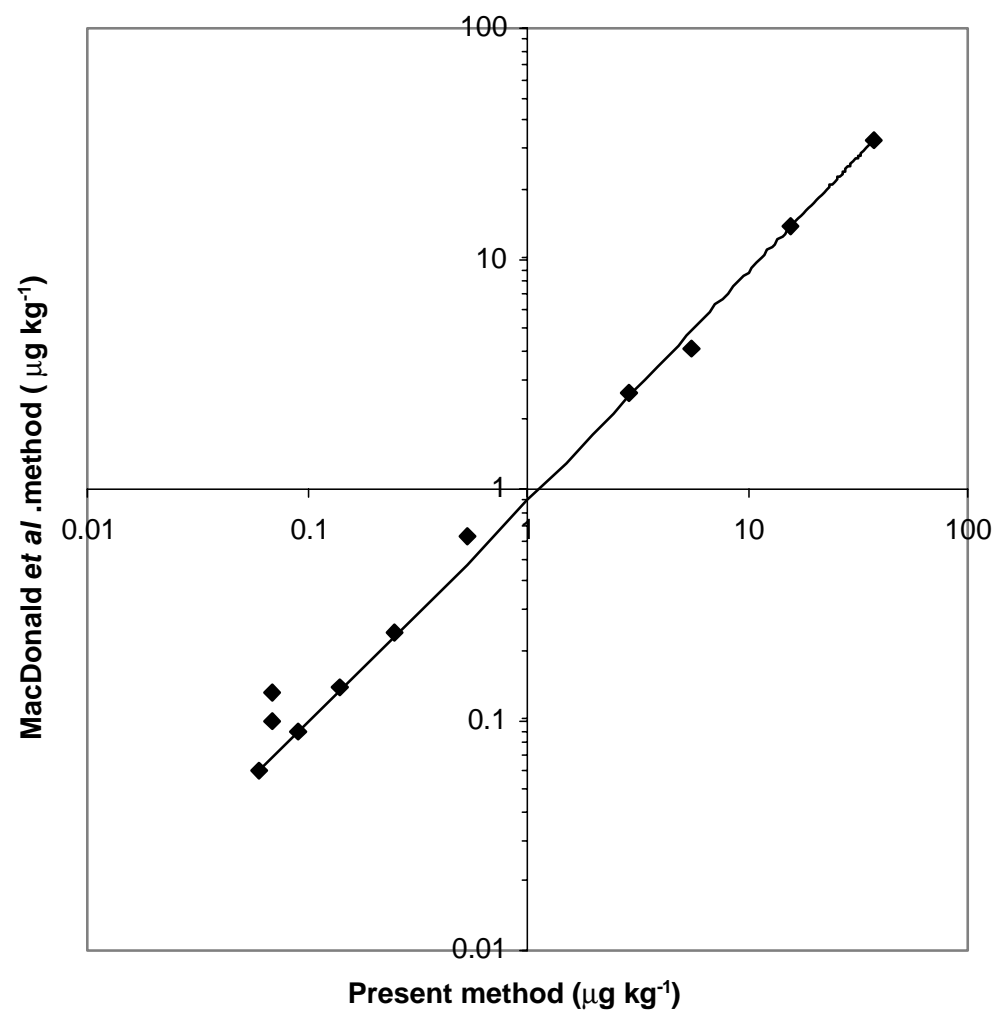

Fig. 2. Linear regression of the present method vs. extraction by MacDonald et al. method [9], for the determination of OTA in 11 contaminated wine grape samples obtained by incubation of grapes with an OTA producing strain and further dilutions of contaminated and blank material. 
Table 3

Relevant statistical parameters of the linear regression between the results obtained for the methods compared regarding OTA content of naturally contaminated grapes

\begin{tabular}{lcccc}
\hline Concentration range $\left(\mu \mathrm{g} \mathrm{kg}^{-1}\right)$ & Number of points & Correlation coefficient, $r$ & Slope, $b \pm \mathrm{tSb}$ \\
\hline $0.06-37.64$ & 11 & 0.9996 & Intercept, $a \pm \mathrm{tSa}^{\mathrm{b}}$ & $0.87 \pm 0.02$ \\
$<1(0.06-0.53)$ & 7 & 0.987 & $0.01 \pm 0.24$ & 0.31 \\
\hline
\end{tabular}

a $95 \%$ confidence limits for slope.

b $95 \%$ confidence limits for intercept.

c Standard deviation of $y$-residuals.
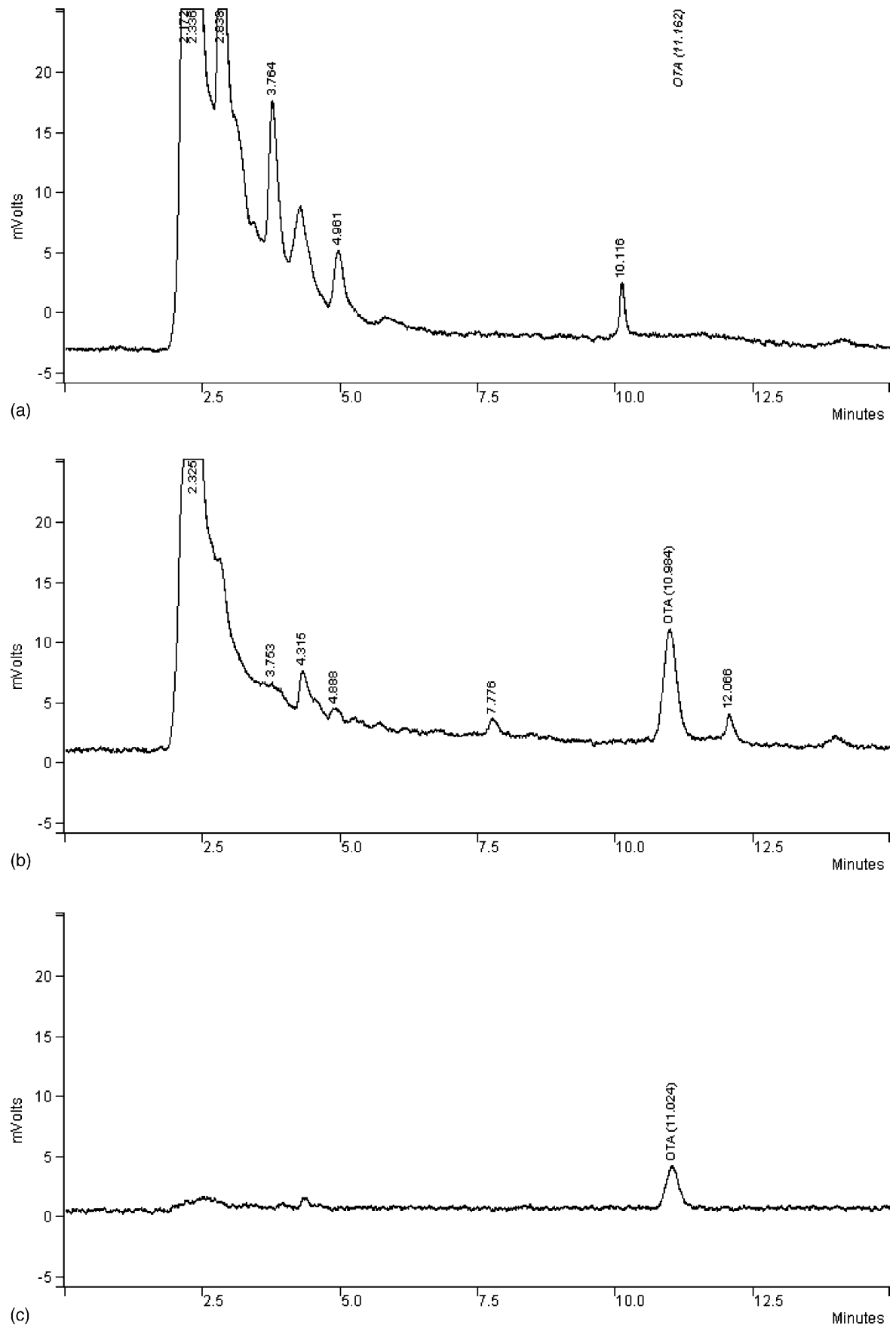

Fig. 3. Typical chromatograms of wine grapes obtained by the method described here: (a) blank sample; (b) positive sample for OTA $\left(0.04 \mu \mathrm{g} \mathrm{kg}{ }^{-1}\right)$; (c) OTA standard solution $\left(0.1 \mu \mathrm{gl}^{-1}\right)$. 
Table 4

OTA concentration levels in Portuguese wine grapes during the 2002 harvest determined with the proposed method

\begin{tabular}{lcl}
\hline Region & Sample code & OTA concentration $\left(\mu \mathrm{g} \mathrm{kg}^{-1}\right)^{\mathrm{a}}$ \\
\hline Vinhos Verdes & 1 & 0.035 \\
& 2 & Below LOD \\
& 3 & Below LOD \\
Douro & 4 & Below LOD \\
& 5 & Below LOD \\
& 6 & Below LOD \\
Ribatejo & 7 & Below LOD \\
& 8 & 0.056 \\
& 9 & 0.061 \\
Alentejo & 10 & Below LOD \\
& 11 & Below LOD
\end{tabular}

${ }^{a}$ Average between duplicates. method and the dilution rate show that the method involving extraction with solution A is more precise $(r=0.999$ against $r=0.978$ for MacDonald et al. method). Therefore, it is in terms of precision that both extraction procedures differ the most, with the method involving extraction with solution A exhibiting better performance. Recently, while the validation of this method was being undertaken, Greek researchers have used a method based on the same extraction principle to detect OTA in dried vine fruits [14], with good recovery rates $(73.5-86.0 \%)$, using spiked samples, indicating that the hydrogen carbonate and PEG solution can be used for OTA extraction from these matrices, too.

\subsection{Analyses of Portuguese wine grapes}

In the survey conducted on Portuguese wine grapes, OTA was detected in three out of the 11 samples tested, in concentrations that ranged from 0.035 to $0.061 \mu \mathrm{g} \mathrm{kg}^{-1}$ (Table 4). The chromatograms obtained (Fig. 3) are acceptable, and
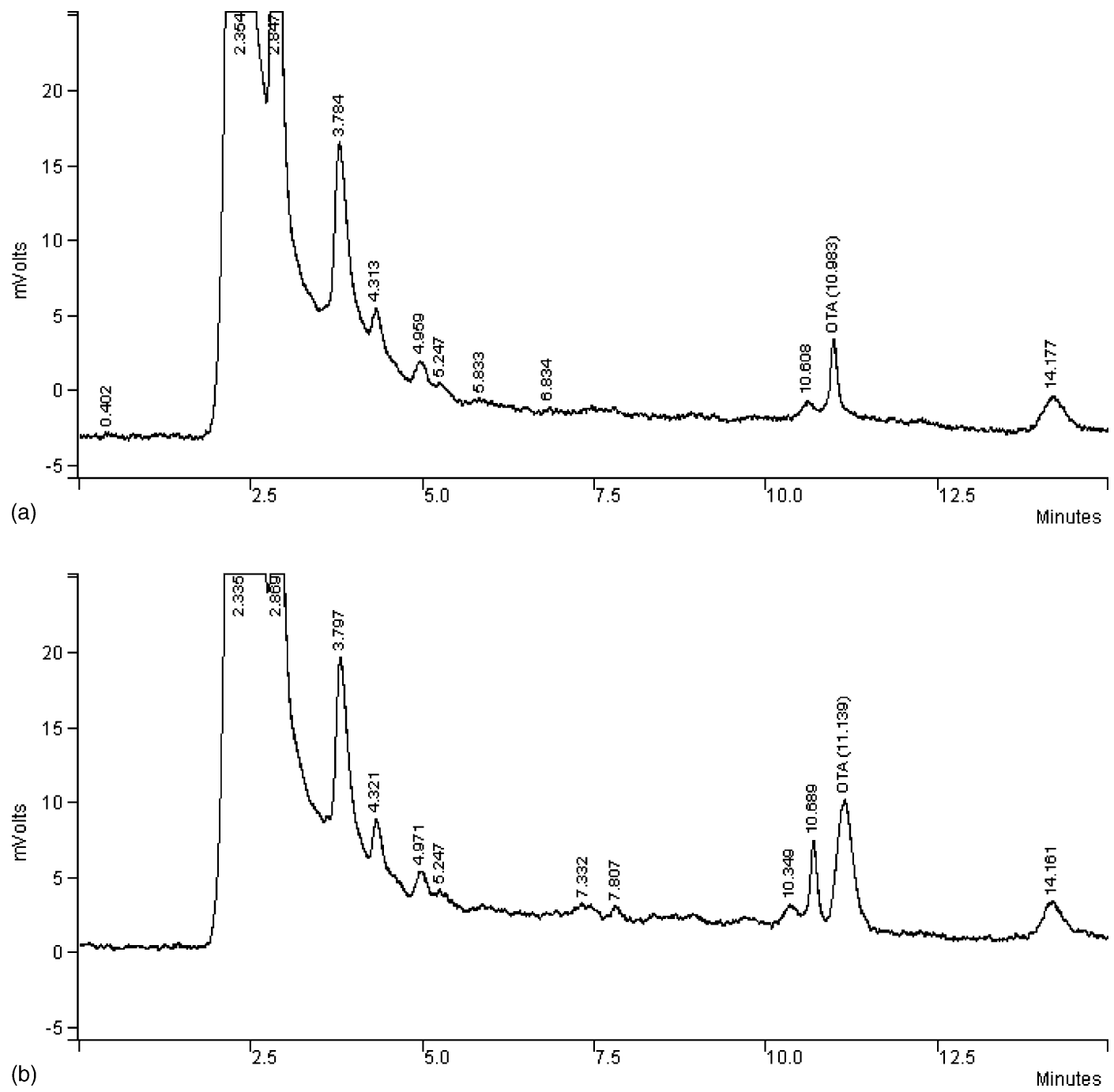

Fig. 4. Example of a chromatogram of a wine grape variety with an interference substance: (a) chromatogram showing an interfering substance near the OTA retention time; (b) same sample after standard addition $\left(0.35 \mu \mathrm{g} \mathrm{kg}^{-1}\right)$. 
free of most interferences, as typically reported when an IAC clean-up is used. However, in some grape varieties, a compound was found with a retention time close to OTA that did not increase height with standard addition (Fig. 4a and $b$ ). The presence of interfering this substances near the OTA retention time in wines has not frequently been reported with IAC clean-up. However, Zimmerli and Dick [5] reported the existence of an interfering compound exactly at the retention time of OTA in grape juice, with a probable natural origin, at levels corresponding to an apparent OTA concentration of $1.4 \mu \mathrm{g} \mathrm{kg}^{-1}$, invalidating their method for this matrix. In our work, in the samples where these compounds were present, the interfering peak never exceeded the height corresponding to $0.3 \mu \mathrm{g} \mathrm{kg}^{-1}$ of OTA, and do not prevent analyte detection or quantification, but require further confirmation by standard addition or OTA methyl ester formation. Probably we have not experienced the same problems as Zimmerli and Dick due to the use of PEG in the extraction solution. Visconti et al. [6] used PEG in solution A because it was found to reduce drastically the number and intensity of additional chromatographic peaks unrelated to OTA.

\section{Conclusions}

The method developed by Visconti et al. [6] for wine analysis has been used as a starting point to develop a method based on the extraction of grapes with hydrogen carbonate and PEG solution. The method developed proved to be reliable, both for spiked and naturally contaminated samples, for in a wide range of OTA concentrations, when plotted against a validated method for dried vine fruits involving extraction with acidified methanol. The method here proposed allows a reduced use of solvents by eliminating them from the extraction step. The analysis for OTA in wine grapes is important in risk assessment studies, making it possible to predict the risk of OTA contamination in wine, and to plan eventual corrective measures. In the 11 samples of Portuguese wine grapes analysed, OTA was detected in three samples, from 0.035 to $0.061 \mu \mathrm{g} \mathrm{kg}^{-1}$.

\section{Safety}

OTA is a toxic compound that needs to be manipulated with care and with the appropriate safety precautions.
Decontamination procedures for laboratory wastes have been reported by the International Agency on Research on Cancer (IARC) [15] and were employed throughout this experimental work.

\section{Acknowledgements}

The authors gratefully acknowledge the support of the EC, Quality of Life Programme (QoL), Key Action 1 (KA1) on Food, Nutrition and Health; contract number QLK1-CT-2001-01761-Wine-Ochra Risk. R. Serra was supported by grant SFRH/BD/1436/2000 from Fundação para a Ciência e Tecnologia.

\section{References}

[1] M. Miraglia, C. Brera, Report on Tasks for Scientific Cooperation, Directorate of General Health and Consumer Protection, 2002.

[2] A. Alves, in: A. Cerdeira, A. Venâncio, A. Alves, P. Barros, T. Simões (Eds.), Impacto da contaminação fúngica sobre a competitividade de vinhos, Micoteca da Universidade do Minho, Braga, 2003, pp. 53-70.

[3] R. Serra, L. Abrunhosa, Z. Kozakiewicz, A. Venâncio, Int. J. Food. Microbiol. 88 (2003) 63.

[4] I. Festas, P. Herbert, L. Santos, M. Cabral, P. Barros, A. Alves, Am. J. Enol. Vitic. 51 (2000) 150.

[5] B. Zimmerli, R. Dick, Food Addit. Contam. 13 (1996) 655.

[6] A. Visconti, M. Pascale, G. Centonze, J. Chromatogr. A 864 (1999) 89.

[7] A. Leitner, P. Zollner, A. Paolillo, J. Stroka, A. PapadopoulouBouraoui, S. Jaborek, E. Anklam, W. Lindner, Anal. Chim. Acta 453 (2002) 33

[8] E. Anklam, J. Stroka, A. Boenke, Food Contr. 13 (2002) 173.

[9] S. MacDonald, P. Wilson, K. Barnes, A. Damant, R. Massey, E. Mortby, M.J. Shepherd, Food Addit. Contam. 16 (1999) 253.

[10] I.M. Santos, N. Lima, World J. Microbiol. Biotechnol. 17 (2001) 215.

[11] D.C. Hunt, B.R. McConnie, N.T. Crosby, Analyst 105 (1980) 89.

[12] Commission directive 2002/26/EC of 13 March 2002 laying down the sampling methods and the methods of analysis for the official control of the levels of ochratoxin A in foodstuffs, Off. J. Eur. Commun. L75 (2002) 38-43.

[13] J. Gilbert, E. Anklam, Trends Anal. Chem. 21 (2002) 468.

[14] I. Stefanaki, E. Foufa, A. Tsatsou-Dritsa, P. Dais, Food Addit. Contam. 20 (2003) 74.

[15] M. Castegnaro, J. Barek, J.M. Fremy, M. Lafontaine, M. Miraglia, E.B. Sansone, G.M. Telling, Laboratory decontamination and destruction of carcinogens in laboratory wastes: some mycotoxins, IARC Scientific Publication No. 113, International Agency for Research on Cancer, Lyon, 1991. 